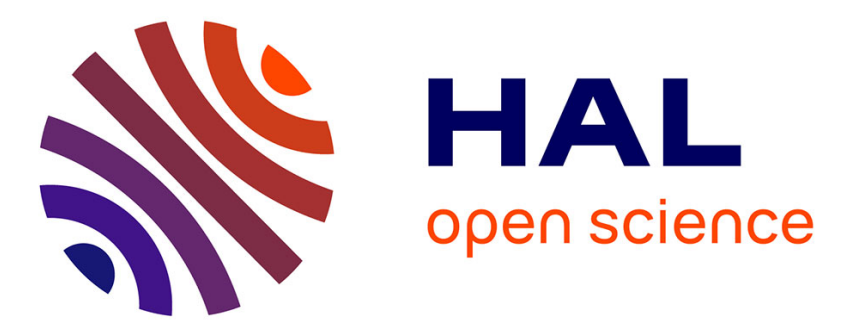

\title{
Unsaturated resilient behavior of a natural compacted sand
}

Hossein Nowamooz, Cyrille Chazallon, Maria Ioana Arsenie, Pierre Hornych, Farimah Masrouri

\section{- To cite this version:}

Hossein Nowamooz, Cyrille Chazallon, Maria Ioana Arsenie, Pierre Hornych, Farimah Masrouri. Unsaturated resilient behavior of a natural compacted sand. Computers and Geotechnics, 2011, 38 (4), pp.491-503. 10.1016/j.compgeo.2011.02.013 . hal-00614031

\section{HAL Id: hal-00614031 \\ https://hal.science/hal-00614031}

Submitted on 14 Mar 2017

HAL is a multi-disciplinary open access archive for the deposit and dissemination of scientific research documents, whether they are published or not. The documents may come from teaching and research institutions in France or abroad, or from public or private research centers.
L'archive ouverte pluridisciplinaire HAL, est destinée au dépôt et à la diffusion de documents scientifiques de niveau recherche, publiés ou non, émanant des établissements d'enseignement et de recherche français ou étrangers, des laboratoires publics ou privés.

\section{(c)(1)}

Distributed under a Creative Commons Attribution| 4.0 International License 


\title{
Unsaturated resilient behavior of a natural compacted sand Hossein
}

\author{
Nowamooz $^{\mathrm{a}, \mathrm{b}}$, Cyrille Chazallon ${ }^{\mathrm{a}}$, Maria Ioana Arsenie ${ }^{\mathrm{a}, \mathrm{b}}$, Pierre Hornych ${ }^{\mathrm{c}}$, \\ Farimah Masrouri ${ }^{\mathrm{b}}$ \\ ${ }^{a}$ Laboratory of Design Engineering, INSA de Strasbourg, 24 Boulevard de la Victoire, 67084 Strasbourg Cedex, France \\ ${ }^{\mathrm{b}}$ Laboratoire Environnement Géomécanique Er Ouvrages, Nancy-Université, Rue du Doyen Marcel Roubault, BP 40, 54501 Vandœuvre-lès-Nancy Cedex, France \\ 'Materials and Pavements Structures Division, Laboratoire Central des Ponts et Chaussées, Route de Bouaye BP4129, 44341 Bouguenais Cedex, France
}

\begin{abstract}
Granular materials are generally used in unbound layers of road pavement structures. The mechanical behavior of these materials is widely studied with repeated load triaxial tests (RLTT) in which the elastic response is defined as the resilient behavior. Usually observed under total stress conditions, the effect of pore pressure changes during loading are not usually included in design. Further, the unbound layers frequently exist under partially saturated conditions. The influence of the unsaturated state, i.e., the suction, on the mechanical behavior, of unbound granular materials for roads has not been sufficiently studied and is generally not taken into account in models used for these materials.

This article presents an experimental study of the repeated load response of a compacted clayey natural sand, and describes a model for the response which includes the effects of soil suction. The response of the proposed model formulated in terms of effective stress is compared with a similar model formulated in terms of total stress. The results from both the effective stress model and the total stress model are compared with the measured volumetric and deviatoric response. It is suggested that since the model parameters for the effective stress formulation are relatively constant for all values of suction (water content), the resilient response can be best captured by an effective stress model.
\end{abstract}

Keywords:

Clayey sand

Unsaturated state

Cyclic loading

Repeated load triaxial tests

Resilient behavior

Soil water retention curve

Effective stress

\section{Introduction}

Low traffic pavements with a thin bituminous surfacing, granular base and sub-base layers represent approximately $60 \%$ of the road network in France. In these pavements, permanent deformations of the unbound layers and of the soil represent the main causes of distress that lead to rutting of the pavement surface.

Recent studies [8], dealing with the improvement of design methods for flexible pavements have pointed out that, in most cases, when the water content increases in the unbound layers, or the soil, on a permanent basis, the decrease in the bearing capacity of these layers leads to rutting. This distress occurs mainly in the granular base and sub-base layers. Despite this knowledge, the rutting of unbound materials is still not well-understood, and it is not taken into account in most pavement analysis and design methods. In the French pavement design method ([16]), which is a mechanistic-empirical design method that is based on linear elastic calculations, the only rutting criterion concerns subgrade soil and consists in limiting the vertical elastic strains at the top of the subgrade. No criterion is applied for the unbound granular layers.

The purpose of this work is to apply this knowledge to pavement design with the aid of an appropriate theoretical analysis and an understanding of the deformation mechanisms. Nonlinear stress-strain relationships are a particular feature of the problem and must be considered in pavement analysis and design. The mechanical processes can be separated into two categories, namely, (i) a short-term mechanical processes and (ii) a long-term mechanical processes. The first category concerns the instantaneous behavior of a flexible pavement, as activated during the passage of a vehicle. The second category concerns the accumulation of permanent deformations, which is not the point of this study.

Repeated load triaxial tests (RLTTs) are commonly used to establish the mechanical characteristics of granular materials and are used to describe either the resilient behavior [10,19,37,22,27] or permanent deformation accumulation $[20,2,33,15]$.

The behavior of unbound granular materials in roads is generally studied in the unsaturated state, but the modeling of this behavior is generally based on total stresses. Nevertheless, a complete description of the material behavior necessitates an effective stress approach with the pore pressures (or pore suctions) are separately controlled or monitored from the applied pressures. Most road materials are coarse-grained and are partially saturated 


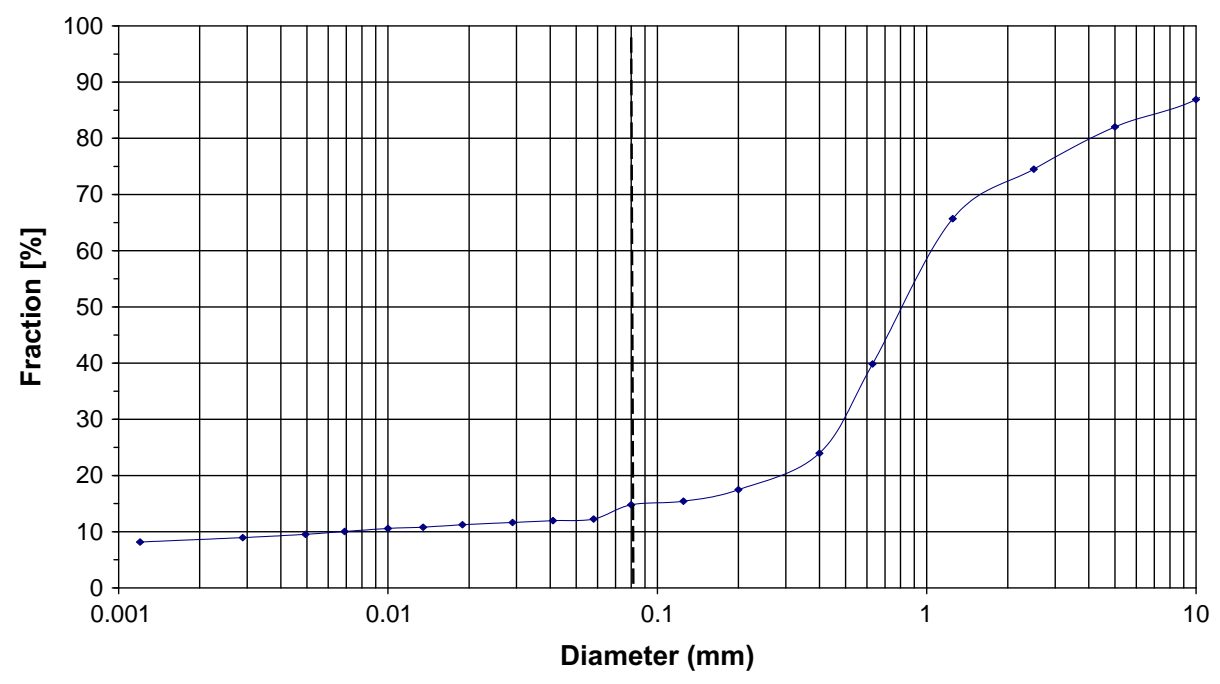

Fig. 1. Particle size distribution curve of Missillac sand.

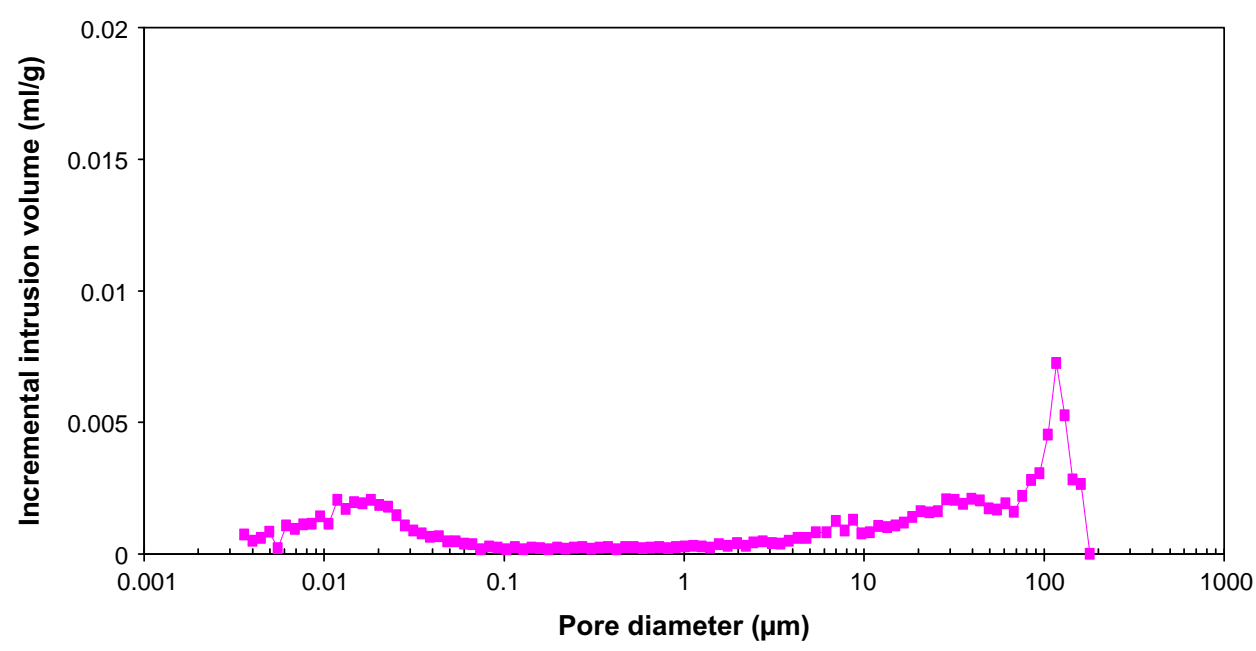

Fig. 2. Distribution of incremental pore volume evaluated from the MIP results.

because they are positioned above the ground water table. However monitoring the pore suctions during each transient pulse of the mechanical loading usually proves to be impossible. For this reason, all testing programs (for example RLTT) determine parameter values for resilient and incrementally-developed plastic strain models in terms of the total, not the effective, stresses. This last point has been recently underlined in a synthesis of the various modeling approaches developed for unbound granular materials in roads [8]. One of the main conclusions from that study related to future work was that the models could be improved by taking into account the unsaturated state of the material and its influence on the mechanical behavior. Experimental work shows that the variation of the water content in cohesive soils and granular materials has a significant influence on their mechanical behavior especially on the resilient modulus, as reported by Rada and Witczak [28], Li and Selig [24], Drumm et al. [10], Yuan and Nazarian [37], Khoury and Zaman [22], Rababah [27].

Unsaturated soils exert an attraction on water, either by capillary action in the pores, between soil particles, or through physicochemical effects. The variation of water content with suction is generally represented by a SWRC in unsaturated soil mechanics. To cover the whole suction range between 0 and $300 \mathrm{MPa}$, the salt solution technique [12] is generally combined with either air overpressure methods $[30,11,3]$ with a maximum imposed suction of about $14 \mathrm{MPa}$ [36] or osmotic techniques [38,9,25]. A comparison between the various methods of controlling suction (osmotic, tensiometric plate, air overpressure, vapor equilibrium and thermocouple measurements) was conducted by Fleureau et al. [14] on a kaolinite slurry over a wide range of suctions from 0.4 up to $180 \mathrm{MPa}$. The pressure necessary to extract water from unsaturated soils, for example, from a densely compacted swelling clay used for engineering barriers in nuclear waste, can be higher than $10 \mathrm{MPa}$. However, a granular soil will have a suction of several tens of $\mathrm{kPa}$; consequently, the tensiometer method [31] is a good option for measuring the suction in this range. The filter paper method $[18,13]$ can be used for any suction measurement, although this method is less precise for the low suction values.

In this context, this article initially presents the hydric characteristics, through the SWRC, and the resilient behavior, through the RLTT results, of a clayey sand (Miscillac sand). These results allow us to define the resilient behavior with the Boyce model [5] in terms of the effective stresses (instead of total stresses as originally developed) over a range of water contents (suction values). This definition finally improves the determination of the model parameters since the same set of parameters can be used for the different water contents (suction values). 


\section{Experimental program}

\subsection{Material}

The Miscillac sand is a clayey sand that is often used as subgrade soil in low traffic pavement. It is sensitive to moisture, and its in situ elastic modulus typically varies between 50 and $100 \mathrm{MPa}$.

The particle size distribution of this material presented in Fig. 1 is continuous $\left(d_{60}=1.10 \mathrm{~mm} ; d_{30}=0.48 \mathrm{~mm} ; d_{10}=0.01 \mathrm{~mm}\right)$, and the maximum particle size is about $10 \mathrm{~mm}$.

The pore size distribution of the Missillac sand was evaluated by a mercury intrusion porosimetry (MIP) test. Fig. 2 presents the variation of incremental mercury intrusion volume versus the pore access diameter. This distribution reveals both micro- and macro-structural levels. The dominant diameter of about $100 \mu \mathrm{m}$ corresponds to the macro-pores of the compacted soil, while their microstructure presents its peak at $0.015 \mu \mathrm{m}$.

In the laboratory, the material was prepared in a Proctor mold with a given water content and compacted with the normal Proctor test procedure. Both the compaction curve and the CBR (California Bearing Ratio) curve of the Missillac sand are shown in Fig. 3. The optimum configuration of the normal Proctor compaction is $w_{\text {opt }}=9 \%$ and $\rho_{d}=2.06 \mathrm{Mg} / \mathrm{m}^{3}$. The CBR curve normally shows a different optimum point: $w_{\text {opt }}=8 \%$ and $C B R=46 \%$. The CBR curve indicates a material that is sensitive to moisture when the loss of CBR is between $w=8 \%$ and $w=11 \%$.

In this paper, we suppose that the SWCC can be represented by samples prepared at various compaction water contents. Effects of compaction water content on the soil structure and the mechanical behavior of the samples are assumed to be small.

\subsection{Soil water retention curve (SWRC)}

To determine the variation of suction with the water content of the soil, laboratory tests were conducted using two methods: the filter paper method [1] and the tensiometer method [23], [34], [29].

The matrix (or matric) and total suction of all the samples, which were statically compacted at the same initial dry density
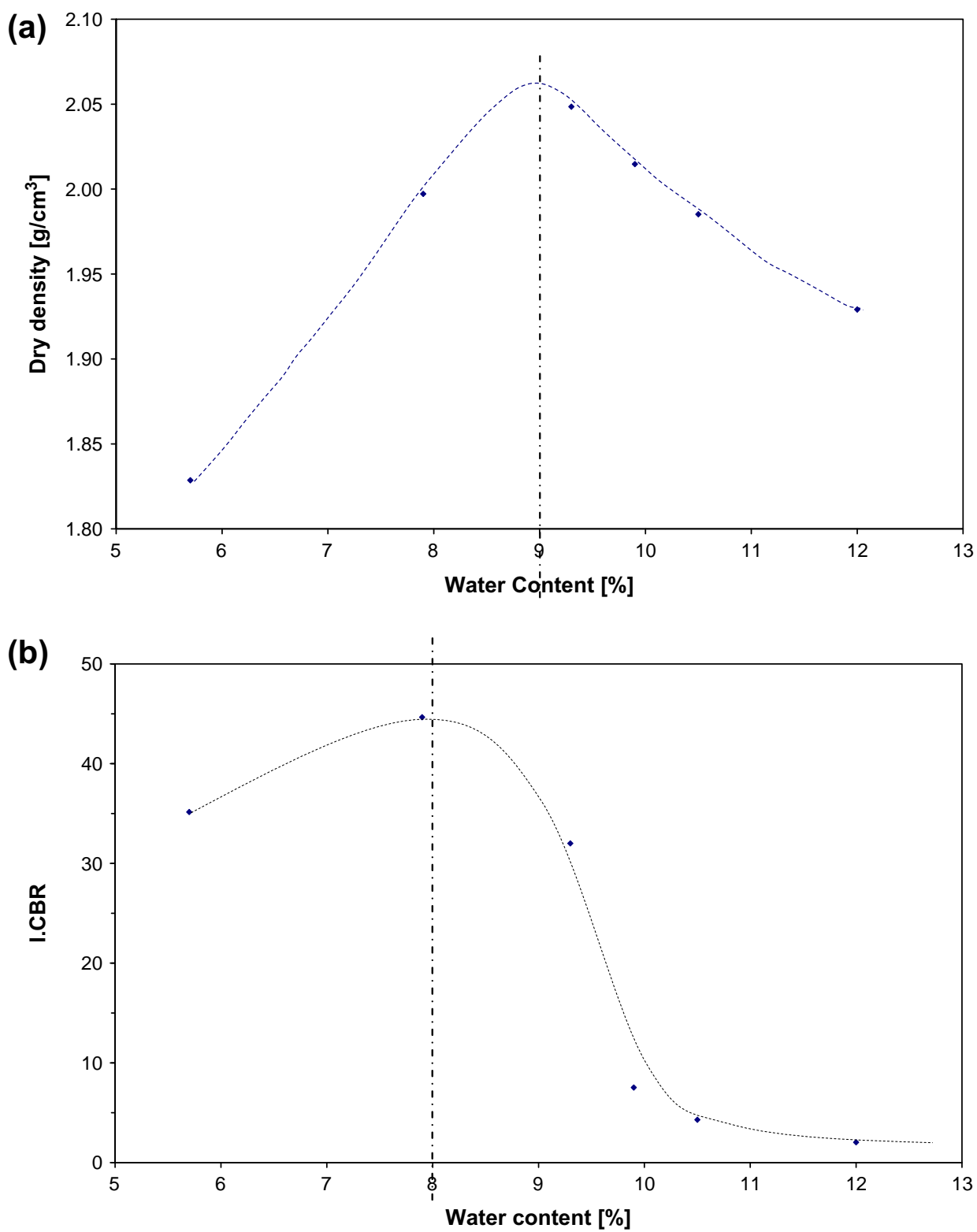

Fig. 3. (a) Normal Proctor compaction and (b) CBR curve of Missillac sand. 


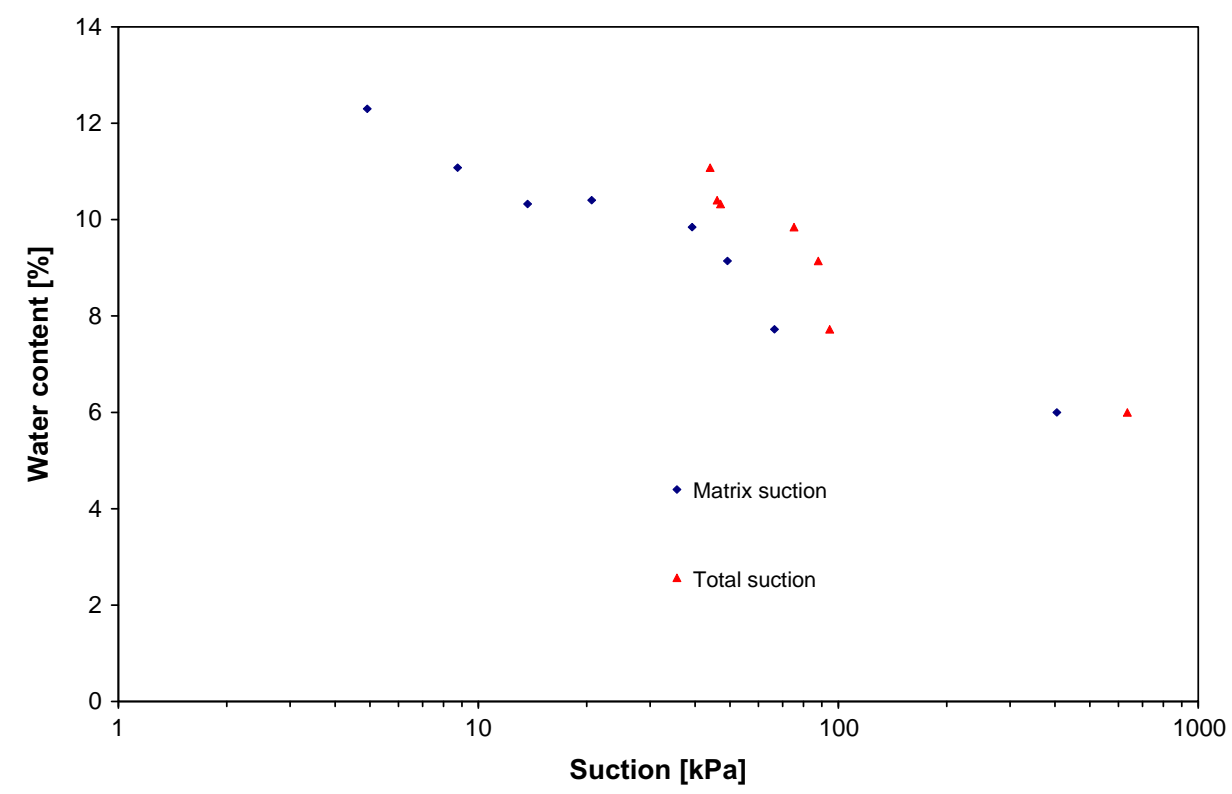

Fig. 4. Variation of the matrix and total suction versus the water content obtained with the filter paper method.

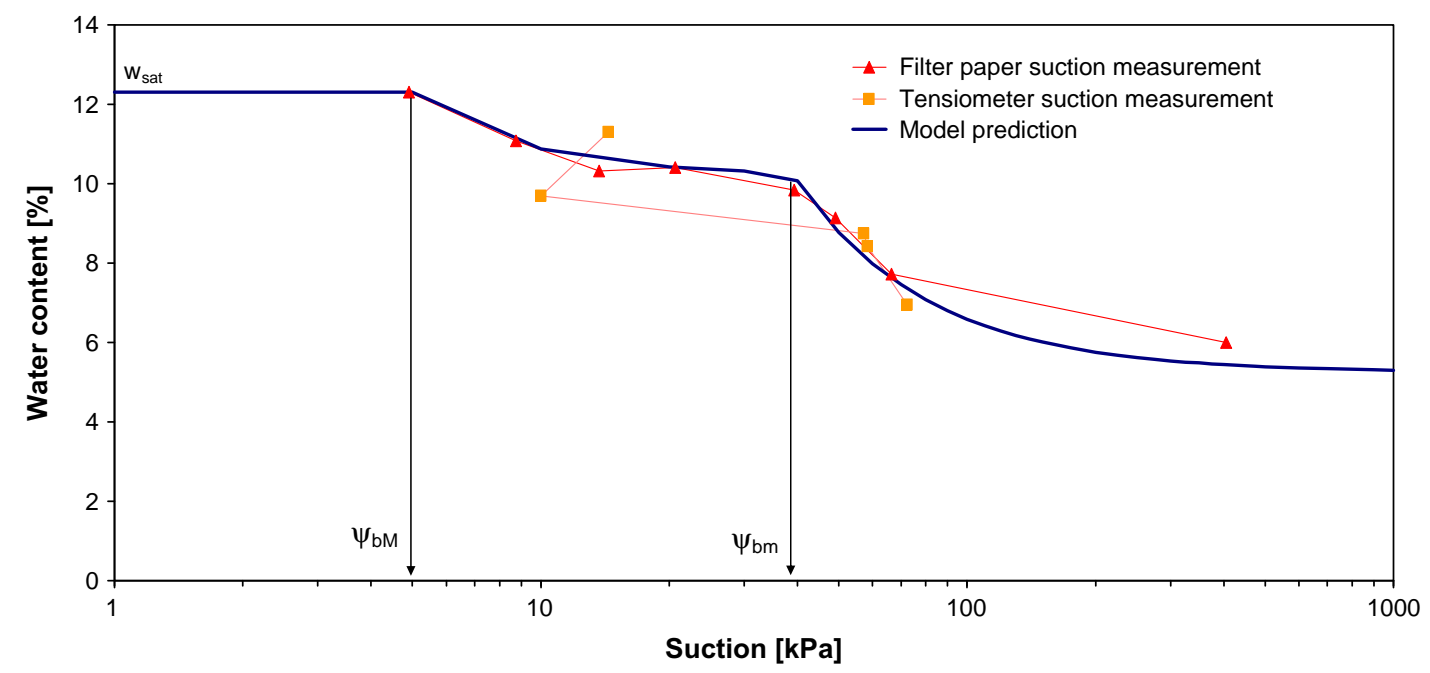

Fig. 5. Comparison of matrix suctions obtained by tensiometer method with the filter paper method and fitted by the Brooks and Corey model [6].

Table 1

Parameters of SWRC of Missillac sand.

\begin{tabular}{lc}
\hline Parameter & Value \\
\hline$\psi_{b M}(\mathrm{MPa})$ & 4.91 \\
$\psi_{b m}(\mathrm{MPa})$ & 39.25 \\
$\lambda_{M}$ & 1.57 \\
$\lambda_{m}$ & 1.40 \\
$w_{r m}(\%)$ & 5.25 \\
$w_{r M}(\%)$ & 10.2 \\
$w_{s}(\%)$ & 12.3 \\
$R M S E$ & 0.035 \\
\hline
\end{tabular}

of $2.0 \mathrm{Mg} / \mathrm{m}^{3}$, were measured for different water contents using the filter paper technique. For this technique, Whatman No. 42 filter paper is enclosed with a soil specimen (without being in contact) in an airtight container for at least two weeks, until the soil reaches a state of equilibrium with the relative humidity (amount of water vapor which exists in a gaseous mixture of air and water vapor) in the measuring chamber, to measure the total suction. For matrix suction measurements, the soil samples were compacted in two layers of $1 \mathrm{~cm}$ thickness. A filter paper was inserted in between two pieces of protective filter papers with larger diameters. The filter paper sandwich was placed between the two soil layers. This test method takes into account the variability of the water content of the filter paper in direct contact with the soil. Fig. 4 presents the variations of the matrix and total suction versus the water content obtained with the filter paper method. Little difference was observed between the total and matrix suction.

The tensiometer technique permits measurements of the matrix suction in the range from 0 to $100 \mathrm{kPa}$. The samples were all compacted at the same initial dry density of $2.0 \mathrm{Mg} / \mathrm{m}^{3}$, at different water contents, with a height of $2 \mathrm{~cm}$ and a diameter of $7 \mathrm{~cm}$. Porous ceramic cups for soaking up the water were carefully put into contact with the samples. The measurements take a few hours to reach an equilibrium state after the installation. Fig. 5 compares the experimental results obtained by the tensiometer method and the filter paper method, and a good correlation is obtained.

Various empirical equations have been suggested to describe the SWRC. Among these equations, the relationships proposed by 
Table 2

Initial state parameters of the tests.

\begin{tabular}{llll}
\hline $\begin{array}{l}\text { Water content, } \\
w(\%)\end{array}$ & $\begin{array}{l}\text { Dry density, } \\
\rho_{d}\left(\mathrm{~g} / \mathrm{cm}^{3}\right)\end{array}$ & Void ratio, $e(-)$ & $\begin{array}{l}\text { Degree of } \\
\text { saturation, } S_{r}(\%)\end{array}$ \\
\hline 7 & 2 & 0.33 & 56 \\
8 & 2 & 0.33 & 65 \\
9.6 & 1.9 & 0.39 & 65 \\
10 & 2 & 0.33 & 80 \\
11 & 1.9 & 0.39 & 74 \\
\hline
\end{tabular}

Brooks and Corey [6], van Genuchten [35] and Fredlund and Xing [17] have been used in geotechnical engineering. In particular, the Brooks and Corey [6] simulation is simple, and its parameters are physically meaningful. The Brooks and Corey equation for the SWRC is written as follows:

$\left\{\begin{array}{l}\frac{w-w_{r}}{w_{s}-w_{r}}=\left(\frac{\psi_{b}}{\psi}\right)^{-\lambda} \quad \psi \geqslant \psi_{b} \\ w=w_{s} \quad \psi \leqslant \psi_{b}\end{array}\right.$

in which $w$ is the water content; $\psi$ is the suction; $\lambda$ is a fitting parameter, which represents the slope of the curve in a logarithmic space; $w_{s}$ is the saturated water content; $\psi_{b}$ is the bubbling pressure (or air entry pressure); and $w_{r}$ is the residual water content.
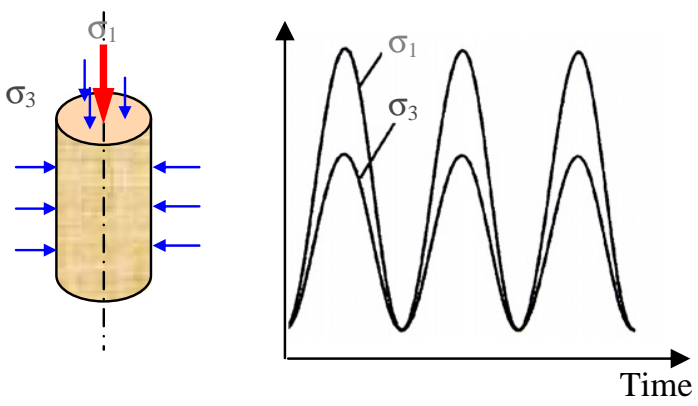

Fig. 6a. Principle of a repeated load triaxial test (RLTT).
Table 3

The water contents and the stress paths followed with repeated load triaxial tests (RLTTS).

\begin{tabular}{lll}
\hline Initial water content $(\%)$ & Initial suction $(\mathrm{kPa})$ & Stress paths $(\Delta q / \Delta p)$ \\
\hline 7 & 90 & $0,0.5,1,2,3$ \\
8 & 60 & $0,0.5,1,2,2.5,3$ \\
9.6 & 45 & $0,0.5,1,2,3$ \\
10 & 40 & $0,0.5,1,2,2.5,3$ \\
11 & 9 & $0,0.5,1,2,3$ \\
\hline
\end{tabular}

For dual porosity soils like the sand studied here (Fig. 2), when the suction exceeds the first air entry value, air starts to fill the macro-pores. At this stage, the micro-pores remain saturated until the suction reaches the second bubbling pressure. Hence, to determine the volumetric water content in bimodal SWRCs, one can employ the superposition principle [7]. In other words, the residual water content of the macro-pores can be used as the saturated water content of the micro-pores. Thus, to adapt the original formula of Brooks and Corey to bimodal SWRCs, the original function is replaced by a three-part equation as follows:

$w= \begin{cases}w_{s} \quad \psi<\psi_{d} \\ w_{r M}+\left(w_{s}-w_{r M}\right)\left(\frac{\psi_{b M}}{\psi}\right)^{-\lambda_{M}} & \psi_{b M}<\psi<\psi_{b m} \\ w_{r m}+\left(w_{r M}-w_{r m}\right)\left(\frac{\psi_{b m}}{\psi}\right)^{-\lambda_{m}} & \psi_{b m}<\psi\end{cases}$

where $w_{s}, w_{r M}, w_{r m}, \psi_{b M}$ and $\psi_{b m}$ are, respectively, the saturated water content, the residual water content of the macro-pores (saturated volumetric water content of the micro-pores), the residual water content of the micro-pores, the bubbling pressure of the macro-pores and the bubbling pressure of the micro-pores. To find a proper curve for the bimodal SWRC that describes the double porosity of the sand employed in this study, $\psi_{b M}, \psi_{b m}$ and $w_{s}$ were directly determined from experimental data, and $w_{r M}, w_{r m}, \lambda_{m}$ and $\lambda_{M}$ were determined by fitting Eq. (2) with the data points. All these parameters are reported in Table 1.

To assess the precision of the Brooks and Corey model for the soil tested, the root-mean-square error (RMSE) was defined as follows:

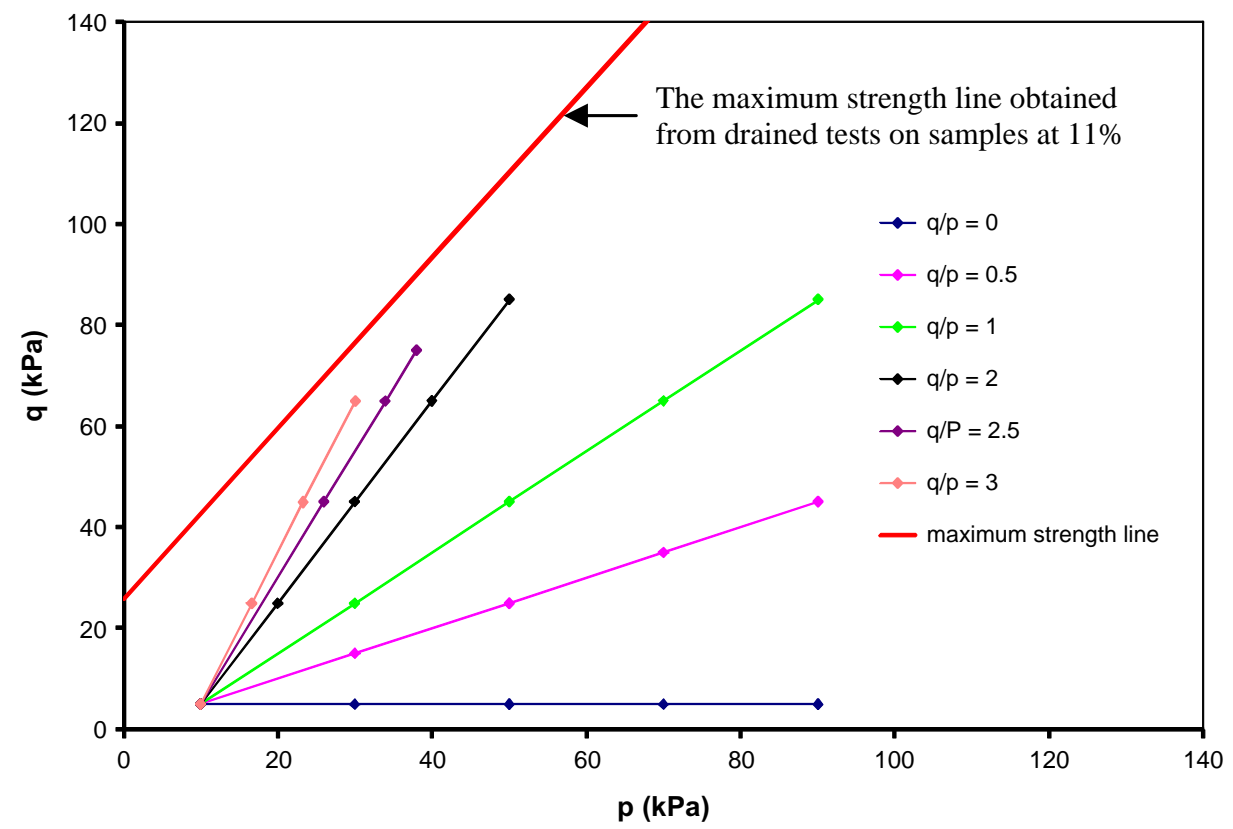

Fig. 6b. Resilient behavior: stress paths applied to Missillac sand for different constant water contents. 

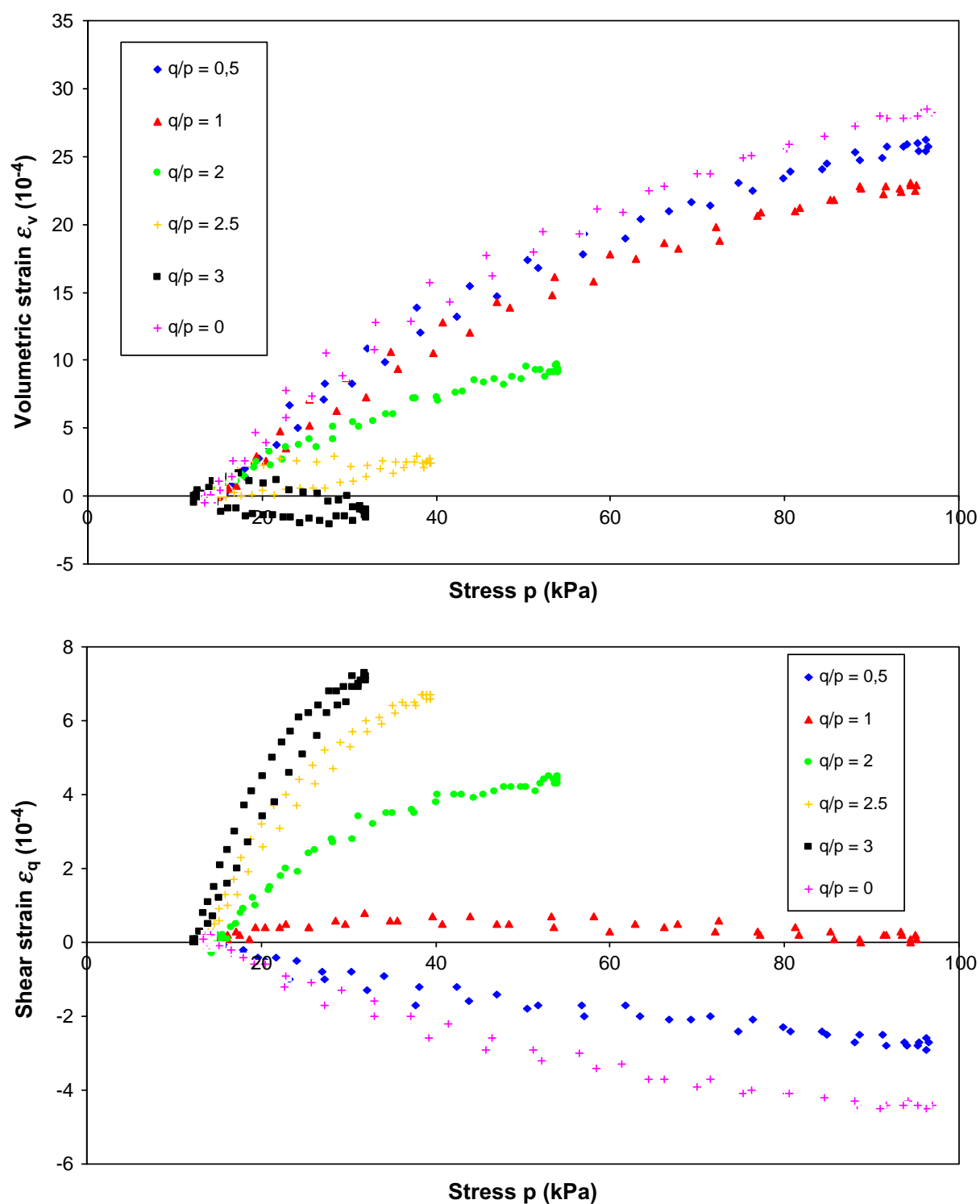

Fig. 7. Volumetric strain and shear strain of a complete cycle for Missillac sand, $w=8 \%$ with the total stress.

RMSE $=\left[\frac{\sum\left(\frac{w-w_{\text {sim }}}{w}\right)^{2}}{n}\right]^{0.5}$

in which $n$ is the number of experimental data points, $w$ is the volumetric water content measured for each specimen and $w_{\text {sim }}$ is the volumetric water content simulated by Eq. (2). The RMSE was minimized to define the parameters of the curves presented in Table 1. The fitted curves are also shown in Fig. 5. It can be concluded that a good agreement is obtained between the model (Eq. (2)) and most of the experimental data.

\subsection{Repeated load triaxial tests (RLTT)}

In laboratory testing procedures, it is well-known that the size of the sample may have an important influence on the results. To minimize size effects, the sample size must be sufficiently large, with regard to the microstructure of the material. For Missillac sand, the samples had a diameter of $76.2 \mathrm{~mm}$ and a height of $147.2 \mathrm{~mm}$. The samples were compacted in a rigid mold using a hammer that is similar to a Proctor hammer in three layers for five different water contents: $7 \%, 8 \%, 9.6 \%, 10 \%$ and $11 \%$ and a dry den- sity of $1.9-2.0 \mathrm{Mg} / \mathrm{m}^{3}$. These samples were different from those used to measure the SWRC. Table 2 presents the initial state of all the studied samples.

The RLTTs were carried out at the Laboratoire Central des Ponts et Chaussées (LCPC) with a cyclic triaxial apparatus for soils, which has a pneumatic loading system. A test procedure with a variable confining pressure (VCP) has been developed, where both the axial load and the confining pressure are cycled. VCP loadings simulate stress paths in unbound pavement layers under wheel loads better than constant confining pressure tests. The tests were performed at a frequency of $1 \mathrm{~Hz}$, with stress-controlled sinusoidal loadings (Fig. 6a). The axial and radial strains of the specimens were measured during the tests using the sample instrumentation.

To study the resilient behavior of the material, the following procedure was used:

- The RLTT is a triaxial test (with open valve) and the water content was measured before and after the repeated loadings.

- The sample was first subjected to conditioning, which consists of applying $10^{4}$ loading cycles at a frequency of $1 \mathrm{~Hz}$, to stabilize the permanent deformations (at the end of this conditioning, 
Table 4

Results of the parameter optimization of the Boyce model based on the total stress concept.

\begin{tabular}{|c|c|c|c|c|c|c|c|}
\hline \multirow[t]{2}{*}{ Initial water content (\%) } & \multirow[t]{2}{*}{ Suction (kPa) } & \multirow[t]{2}{*}{ Stress paths $(\Delta q / \Delta p)$} & \multicolumn{5}{|c|}{ Model parameters } \\
\hline & & & $K_{a}$ & $G_{a}$ & $n$ & $\gamma$ & $\mathrm{CC}$ \\
\hline 7 & 90 & $0,0.5,1,2,3$ & 10.56 & 28.85 & 0.30 & 0.50 & 0.82 \\
\hline 8 & 60 & $0,0.5,1,2,2.5,3$ & 15.85 & 30.60 & 0.39 & 0.60 & 0.83 \\
\hline 9.6 & 45 & $0,0.5,1,2,3$ & 13.92 & 24.47 & 0.37 & 0.59 & 0.88 \\
\hline 10 & 40 & $0,0.5,1,2,2.5,3$ & 18.10 & 37.65 & 0.35 & 0.65 & 0.93 \\
\hline 11 & 9 & $0,0.5,1,2,3$ & 11.32 & 19.21 & 0.35 & 0.48 & 0.79 \\
\hline Average value & & & 13.95 & 28.16 & 0.35 & 0.56 & - \\
\hline
\end{tabular}

(a) $\mathrm{w}=7 \%$
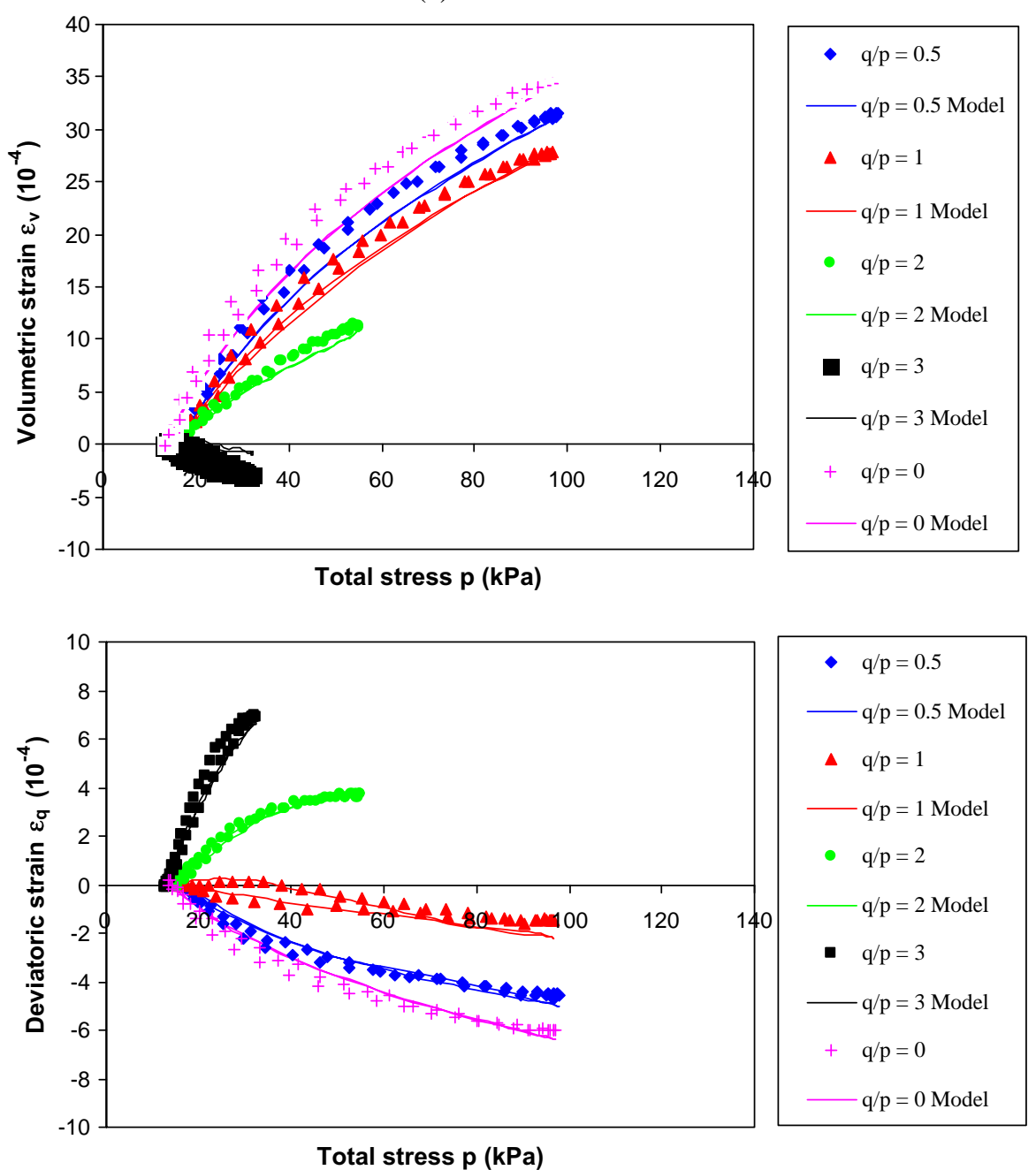

Fig. 8. Evolution of the $\varepsilon_{v}$ and $\varepsilon_{q}$ values based on the total stress concept for $\Delta q / \Delta p=0,0.5,1,2,2.5$ and 3 at two different water contents: (a) $w=7 \%$ and (b) $w=11 \%$.

the increase in the axial plastic deformation was lower than $10^{-8}$ per cycle). The cyclic stresses applied during the conditioning were $(\Delta p, \Delta q)=(40 \mathrm{kPa}, 80 \mathrm{kPa})$ from an initial state of stresses $\left(p_{0}, q_{0}\right)=(10 \mathrm{kPa}, 5 \mathrm{kPa})$,where $p$ is the mean normal stress and $\mathrm{q}$ is the deviatoric stress. For a triaxial test, $p$ and $q$ are defined by:

$p=\left(\sigma_{1}+2 \sigma_{3}\right) / 3$

and

$q=\sigma_{1}-\sigma_{3}$ where $\sigma_{1}$ and $\sigma_{3}$ are the major and minor principal stresses.

- Then, to study the resilient behavior, a series of short loadings (100 cycles) were applied with different stress paths $(\Delta q / \Delta p)$ and different maximum stress levels $\left(p_{\max }, q_{\max }\right)$. Six stress paths were studied $(\Delta q / \Delta p=0 ; 0.5 ; 1 ; 2 ; 2.5 ; 3)$ (Fig. 6b) and three or four stress levels were applied for each stress path. For each load sequence, the last cycle was used to determine the resilient behavior.

Table 3 summarizes the five or six stress paths for each value of the water content. The SWRC was used to estimate the suction corresponding to each value of the water content because the water 
(b) $\mathrm{w}=11 \%$
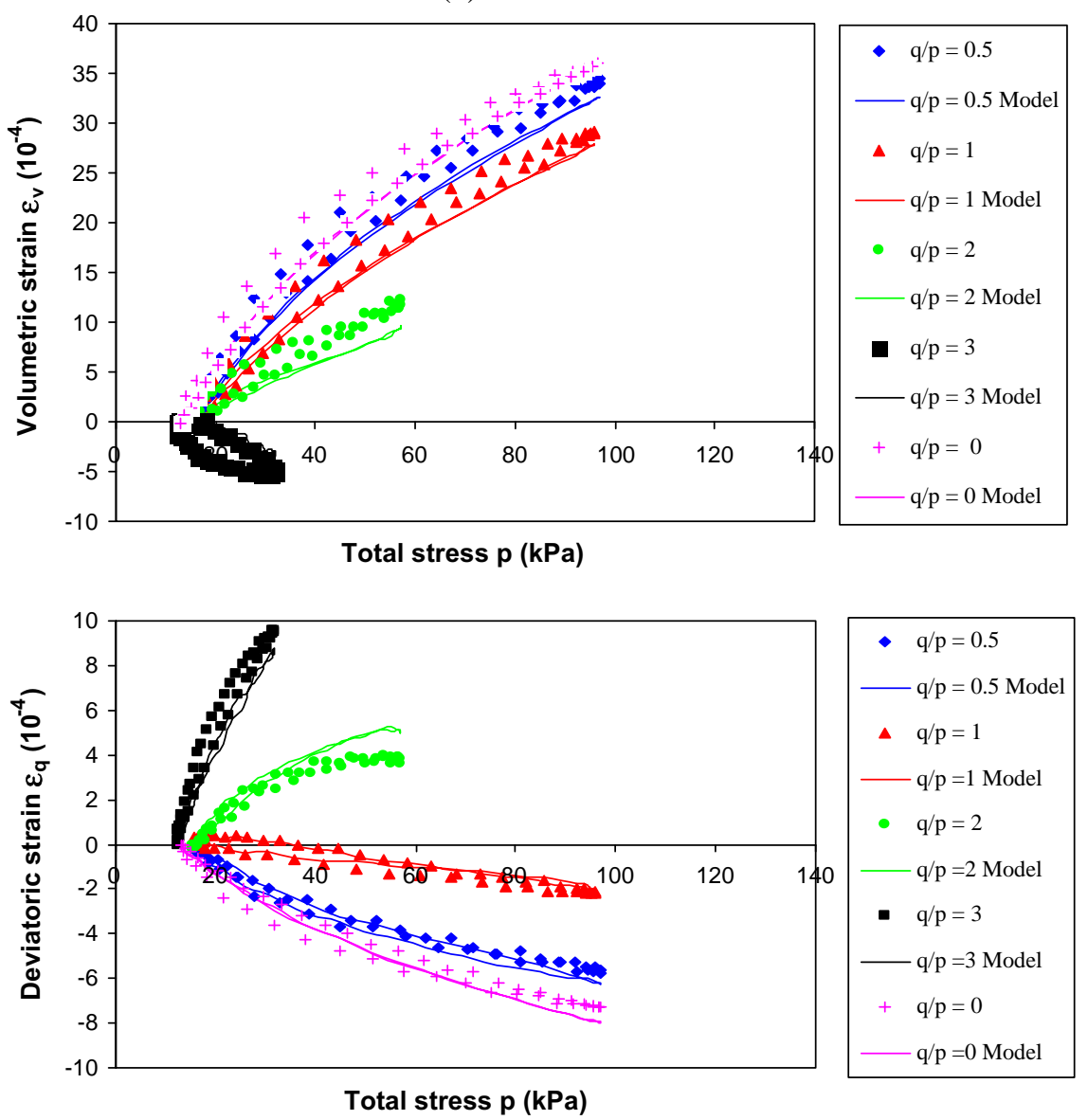

Fig. 8 (continued)

Table 5

Results of the parameter optimization of the Boyce model based on the effective stress concept.

\begin{tabular}{|c|c|c|c|c|c|c|c|}
\hline \multirow[t]{2}{*}{ Initial water content (\%) } & \multirow[t]{2}{*}{ Suction (kPa) } & \multirow[t]{2}{*}{ Stress paths $(\Delta q / \Delta p)$} & \multicolumn{5}{|c|}{ Model parameters } \\
\hline & & & $K_{a}$ & $G_{a}$ & $n$ & $\gamma$ & $\mathrm{CC}$ \\
\hline 7 & 90 & $0,0.5,1,2,3$ & 1.31 & 20.00 & 0.07 & 0.59 & 0.76 \\
\hline 8 & 60 & $0,0.5,1,2,2.5,3$ & 2.00 & 20.65 & 0.07 & 0.62 & 0.80 \\
\hline 9.6 & 45 & $0,0.5,1,2,3$ & 1.13 & 19.10 & 0.04 & 0.59 & 0.86 \\
\hline 10 & 40 & $0,0.5,1,2,2.5,3$ & 3.81 & 25.02 & 0.11 & 0.65 & 0.88 \\
\hline 11 & 9 & $0,0.5,1,2,3$ & 3.63 & 20.31 & 0.10 & 0.50 & 0.80 \\
\hline Average value & & & 2.38 & 21.01 & 0.08 & 0.59 & - \\
\hline
\end{tabular}

content of the sample was not modified during the cyclic tests and the suction was assumed to be constant during the loading. Additionally, the small volumetric and deviatoric strains will modify slightly the initial void ratio equal to 0.33 . In other words, assuming the void ratio values being equal to their initial values, the loading over the various stress paths was assumed to not result in significant changes of the degree of saturation in the samples.

Fig. 7 shows examples of cycles of the volumetric strain $\varepsilon_{v}$ and shear strain $\varepsilon_{q}$ that were obtained for the different stress paths for the tests with a water content of $8 \%$. The cycles show that the behavior of the soil is nonlinear, and depends on the mean stress $p$ and the stress path $\Delta q / \Delta p$.

\section{Modelling results}

\subsection{Boyce model}

If routine pavement design is based on linear elastic calculation using constant Young modulus and constant Poisson ratio for each layer, then advanced pavement design requires improved elasticity models that account for nonlinear behavior with finite element calculations. A comparison of the most widely used elasticity models in pavement design can be found in the following Ref. [8].

Consequently, the nonlinear elastic model of Boyce [5] is a good option for pavement modeling to ensure that the evaluation of the stress, strain, and deflection in the pavement is valid. 
(a) $\mathrm{w}=7 \%$

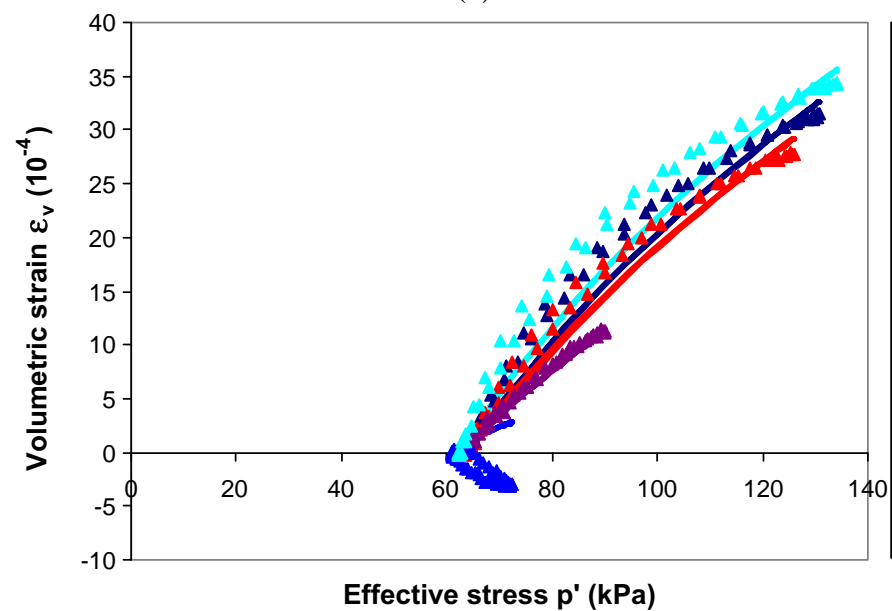

Effective stress p' (kPa)
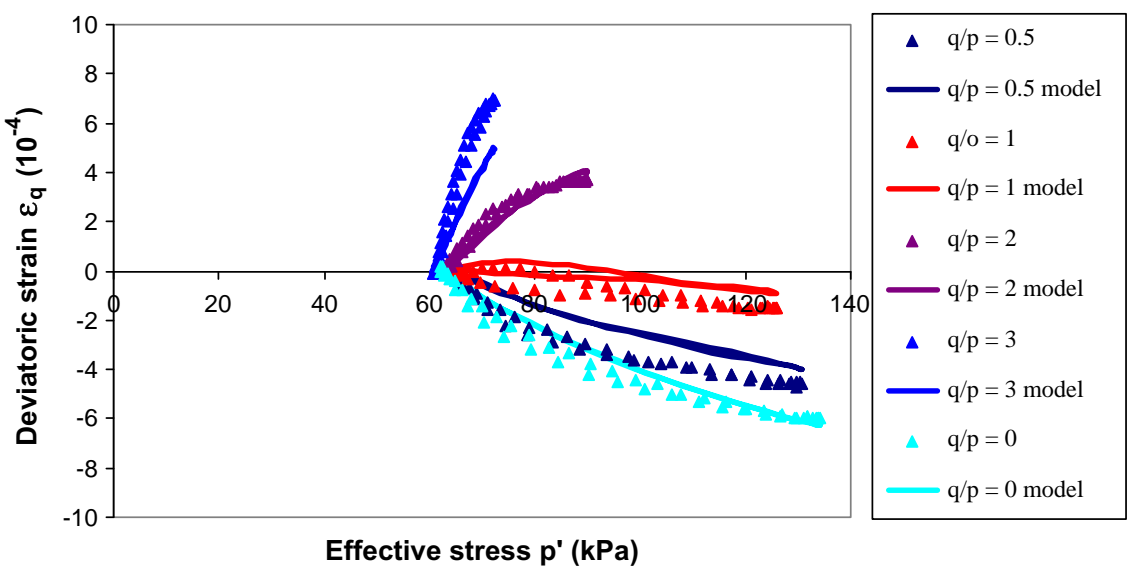

Effective stress p' (kPa)

Fig. 9. Evolution of $\varepsilon_{v}$ and $\varepsilon_{q}$ values based on the effective stress concept for $\Delta q / \Delta p=0,0.5,1,2,2.5$ and 3 at two different water contents (a) $w=7 \%$ and (b) $w=11 \%$.

In 1980, Boyce presented some basis for subsequent work on the stress-dependent modeling of the resilient response of cyclically loaded unbound granular materials. The anisotropy of the pavement materials is increasingly being recognized as a property that must be modeled to adequately describe the pavement mechanical behavior [32]. The Boyce model was modified to include the anisotropy in the early 1990s [21]. Hornych and co-workers introduced the anisotropy by multiplying the principal vertical stress, in the expression of the elastic potential by a coefficient of anisotropy $\gamma$ so that $p$ and $q$ are redefined as follows:

$p^{*}=\frac{\gamma \cdot \sigma_{1}+2 \cdot \sigma_{3}}{3}$

and

$q^{*}=\gamma \cdot \sigma_{1}-\sigma_{3}, \quad 0<\gamma<1$

and the stress-strain relationships are defined as:

$\Delta \varepsilon_{q}^{*}=\frac{2}{3} \cdot\left(\Delta \varepsilon_{1}^{*}-\Delta \varepsilon_{3}^{*}\right)=\frac{\Delta q^{*}}{3 \cdot G_{r}}$

and

$\Delta \varepsilon_{v}^{*}=\Delta \varepsilon_{1}^{*}+2 \Delta \varepsilon_{3}^{*}=\frac{\Delta p^{*}}{K_{r}}$

These relations yield $K_{r r}$ and $G_{r}$, the bulk and shear moduli, respectively as [21]:
$K_{r}=\frac{\left(\frac{p^{*}}{p_{a}}\right)^{1-n}}{\frac{1}{K_{a}}-\frac{\beta}{K_{a}} \cdot\left(\frac{q^{*}}{p^{*}}\right)^{2}}$

and

$G_{r}=\frac{\left(\frac{p^{*}}{p_{a}}\right)^{1-n}}{\left(\frac{1}{G_{a}}\right)}$

and

$\beta=(1-n) \frac{K_{a}}{6 G_{a}}$

where $p_{a}$ is the atmospheric pressure and $K_{a}, G_{a}, \gamma$, and $n$ are model parameters, which are determined with the least square method.

The suction $s$ can be taken into account by the following equations [4] where

$\sigma_{i j}^{\prime}=\left(\sigma_{i j}-u_{a} \delta_{i j}\right)+\chi \cdot\left(u_{a}-u_{w}\right) \delta_{i j}=\left(\sigma_{i j}-u_{a} \delta_{i j}\right)+\chi \cdot s \delta_{i j}$

and

$s=u_{a}-u_{w} \quad$ and $\quad 0 \leqslant \chi \leqslant 1, \quad i=1,2$, or 3

where $u_{a}$ is the pore air pressure, $u_{w}$ is the pore water pressure, $\chi$ is the bishop parameter (taken equal to the degree of saturation of the soil), and $\sigma_{i j}^{\prime}$ is the effective stress tensor. Actually there are lots of propositions for the $\chi$ parameter in the literature [26]. Since our 
(b) $\mathrm{w}=11 \%$
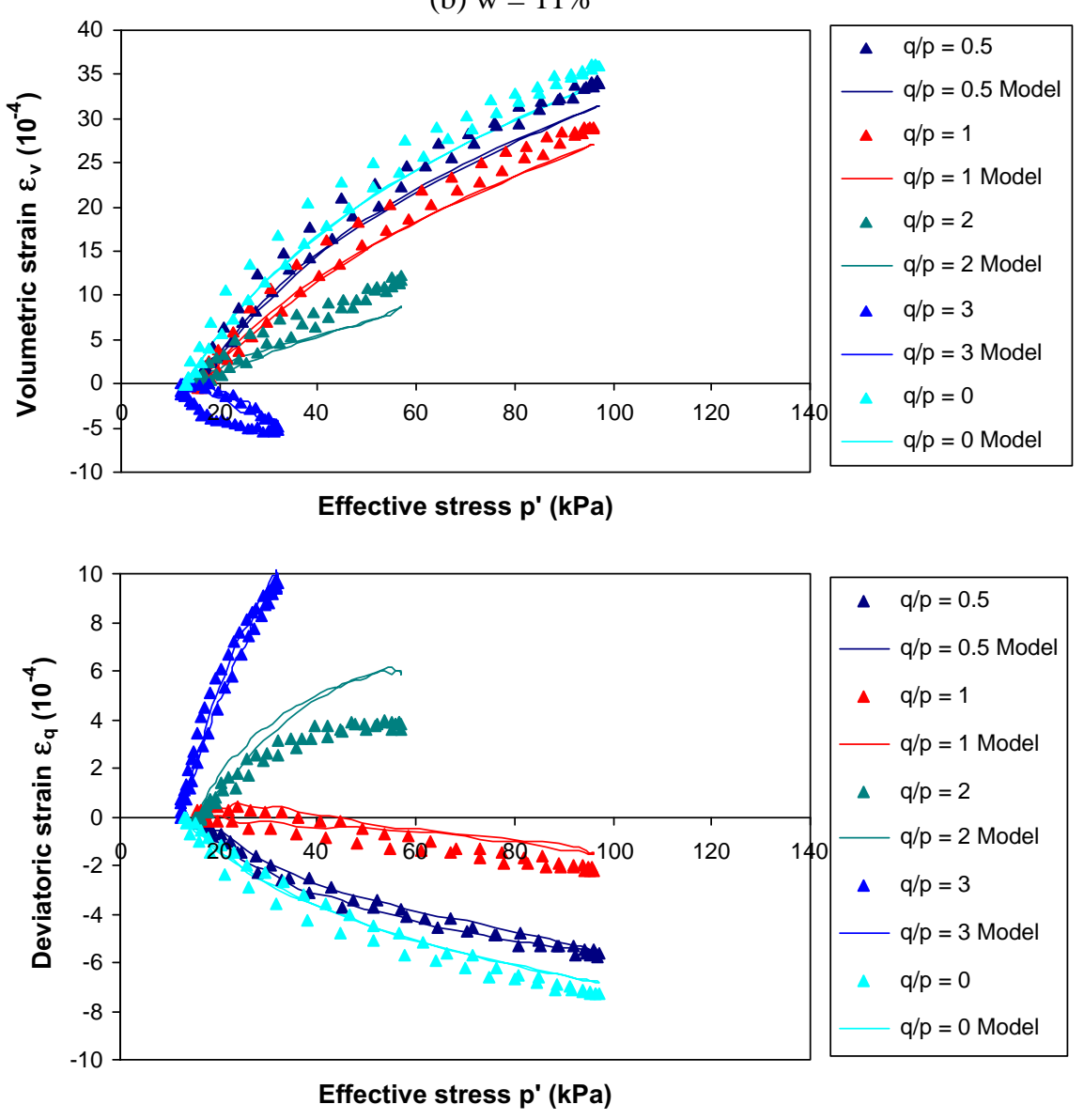

Fig. 9 (continued)

material is a granular one, we choose the simplest assumption $\chi=$ Sr.The following expressions can be proposed for the effective stress and the volumetric and deviatoric strains:

$\begin{aligned} p^{\prime} & =\frac{\left(\gamma \sigma_{1}-u_{a}\right)+\chi \cdot s+2 \cdot\left(\sigma_{3}-u_{a}\right)+2 \chi \cdot s}{3} \\ & =\left(p^{*}-u_{a}\right)+\chi \cdot s\end{aligned}$

$q^{\prime}=\left(\gamma \cdot \sigma_{1}-u_{a}\right)+\chi \cdot s-\left(\sigma_{3}-u_{a}\right)-\chi \cdot s=\gamma \cdot \sigma_{1}-\sigma_{3}=q^{*}$

$\varepsilon_{v}=\frac{p^{\prime n}}{p_{a}^{n-1}} \cdot\left[\frac{\gamma+2}{3 \cdot K_{a}}+\frac{n-1}{18 \cdot G_{a}} \cdot(\gamma+2) \cdot\left(\frac{q^{*}}{p^{\prime}}\right)^{2}+\frac{\gamma-1}{3 \cdot G_{a}} \cdot \frac{q^{*}}{p^{\prime}}\right]$

$\varepsilon_{q}=\frac{2}{3} \cdot \frac{p^{\prime n}}{p_{a}^{n-1}}$

$\cdot\left[\frac{\gamma-1}{3 \cdot K_{a}}+\frac{n-1}{18 \cdot G_{a}} \cdot(\gamma-1) \cdot\left(\frac{q^{*}}{p^{\prime}}\right)^{2}+\frac{2 \cdot \gamma+1}{6 \cdot G_{a}} \cdot \frac{q^{*}}{p^{\prime}}\right]$

\subsection{Modeling based on total stress concept}

The Boyce model is based on the total stress $\left(\sigma_{i j}^{\prime}=\sigma_{i j}, \chi=0\right.$ in Eqs. (13)-(16) and was first applied separately for all the stress paths $\Delta q / \Delta p=0,0.5,1,2,2.5$ and 3 for each water content. To improve the determination of the Boyce model parameters for the tested soils, a correlation coefficient CC was maximized for both the $\varepsilon_{v}$ and $\varepsilon_{q}$ values with a single regression. The parameters $K_{a}$,
$G_{a}, n, \gamma$ are determined with the least square method, and they are shown in Table 4 together with the CC values for the different suctions. Note that three experimental values of $\varepsilon_{v}$ and $\varepsilon_{q}$ were used for the parameter determinations for each value of the water content and along each stress path. These values were determined at three different mean stresses. The optimized parameters produce a good correlation between the estimated and experimental $\varepsilon_{v}$ and $\varepsilon_{q}$ values (based on Eqs. (17) and (18) for all water contents. Fig. 8 shows the results for the samples with $7 \%$ and $11 \%$ water content.

\subsection{Modeling based on effective stress concept}

The effective stress concept was used with the Boyce model (Eqs. (17) and (18)). The same procedure was then applied to determine the Boyce model parameters. To obtain the effective stress values, two assumptions were made:

- Because the water contents of the sample were not modified during the cyclic triaxial tests, the suction values were assumed to be constant throughout the loading and equal to their initial values presented in Fig. 5.

- The $\chi$ parameter was taken to equal to the initial degree of saturation of the samples (Table 2) based on the Bishop equation (Eq. (13)).

Table 5 summarizes the optimized parameters $K_{a}, G_{a}, n, \gamma$ as well as the CC values for different initial water contents. A good 

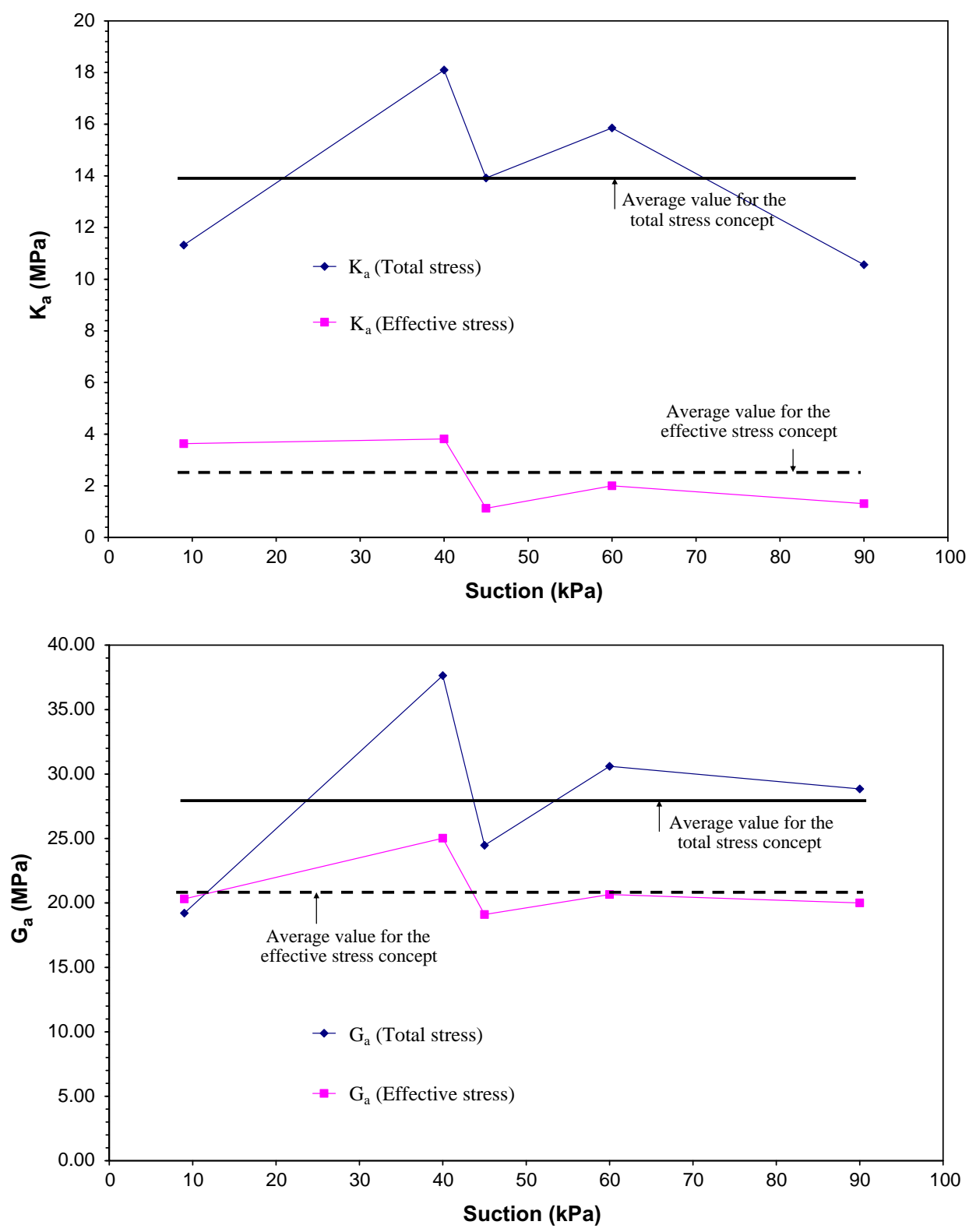

Fig. 10. Variation of $K_{a}, G_{a}, n$ and $\gamma$ (parameters of the Boyce model) with suction.

agreement between the experimental and predicted $\varepsilon_{v}$ and $\varepsilon_{q}$ values (Eqs. (17) and (18)) for the different stress paths at different water contents was obtained based on these optimized parameters. Fig. 9 shows the results for samples with $7 \%$ and $11 \%$ water content.

\subsection{Comparison between the two concepts}

The variation of the $K_{a}, G_{a}, n$ and $\gamma$ parameters with the suction based on the total and effective stress concept are presented in Fig. 10. The average value of each parameter is also reported in Fig. 10 and in Tables 4 and 5. For the model developed in terms of the total stress concept, the parameters $K_{a}, G_{a}, n$ rise then fall as the suction increases, while $\gamma$ remains almost constant with suction. On the other hand, for the model developed in terms of the effective stress concept, the suction seems to have less influence on the parameters and less deviation from the average value, especially for $K_{a}$ and $G_{a}$.
In other words, the Boyce model with constant $K_{a}, G_{a}, n$ and $\gamma$ parameters can be applied for unsaturated soils by simply considering the effective stresses for all the experimental water contents. Consequently, the number of tests used to predict the resilient behavior can be significantly reduced for practical applications.

\section{Conclusion}

This article initially presents the main path of the SWRC of a compacted natural sand (Miscillac sand) using two different suction methods (filter paper and tensiometer) to measure the matrix and total suction range between 0 and $100 \mathrm{kPa}$. These techniques allow one to obtain the SWRC of the compacted samples and to deduce the suction corresponding to a given water content. Note that all the samples were compacted at a similar dry density. These experimental results, in addition to their applications to modeling, provide a good database for comparing the accuracy of each suction measurement method in a range near the saturated state. 

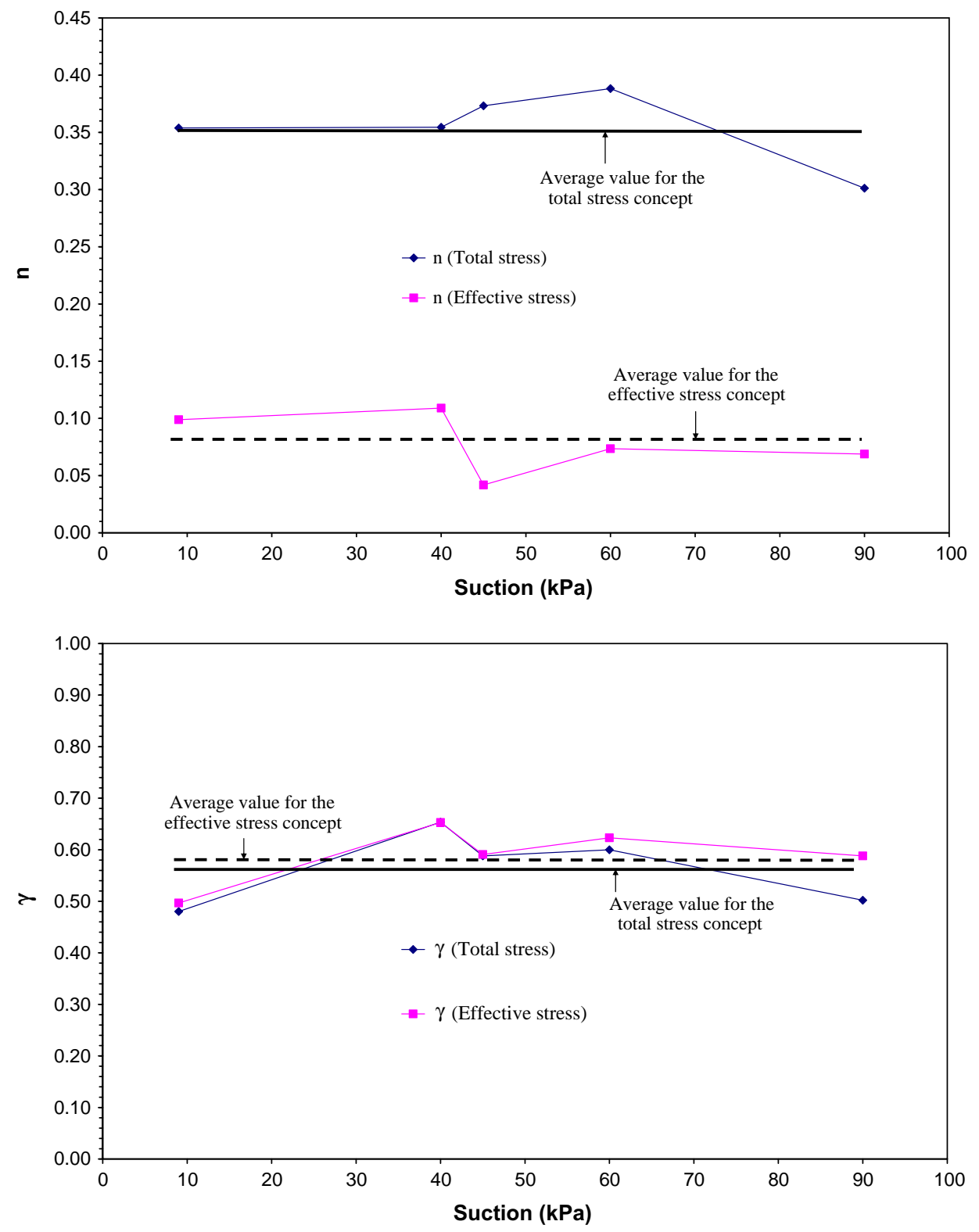

Fig. 10 (continued)

Generally, we can find a good correspondence between the suction curves.

Next, the resilient behavior of these samples was studied with RLTTs at different water contents and six stress paths with stress ratios $\Delta q / \Delta p$ varying from zero up to three. The suction values were assumed to be equal to their initial values because no loss of water was observed at the end of the experiments.

Finally, suction was added in the nonlinear elastic model proposed by Boyce [5], to determine the effective stress state for the different cyclic triaxial tests. The simulations of the resilient behavior with the model, expressed in terms of effective stresses, confirms the capacity of the model to capture the general trend of the experiments. Furthermore, the effective stress concept leads to a less variable set of parameters than the total stress concept for all water contents. This suggests that the number of tests used to predict the resilient behavior for different moisture conditions can be reduced.

The influence of the water content on the bearing capacity of low traffic pavements is not currently taken into account. How- ever, the water content of the unbound layers changes in a year, for example between summer and spring (thaw period) in cold regions or if the pavement drainage is not efficient. It has been proven that there is a strong link between the variation of the bearing capacity of low traffic pavement and the water content of the unbound layers. The use of the proposed model will assist in determining the critical water contents for the design.

\section{References}

[1] ASTM D 5298 - 94. Standard test method for measurement of soil potential (suction) using filter paper 4.09; 1995. p. 154-9.

[2] Allou F, Chazallon C, Hornych P. A numerical model for flexible pavements rut depth evolution with time. Int J Numer Anal Methods Geomech 2007;31:1-22.

[3] Alonso EE, Romero E, Hoffmann C, Garcia-Escudero E. Expansive bentonite/ sand mixtures in cyclic controlled suction drying and wetting. Eng Geol 2005;81:213-26.

[4] Bishop AW, Blight GE. Some aspects of effective stress in saturated and partially saturated BishopBSoils. Geotechnique 1963;13:177-97.

[5] Boyce JR. A non linear model for the elastic behaviour of granular materials under repeated loading. In: International symposium on soils under cyclic and transient loading, Swansea; 1980. p. 285-94. 
[6] Brooks RH, Corey AT. Hydraulic properties of porous medium. Hydrology paper, No. 3. Fort Colins (Colo): Civ. Eng. Dep., Colorado State Univ.; 1964.

[7] Burger CA, Shakelford CD. Evaluating dual porosity of pelletized diatomeceous earth using bimodal soil-water characteristic curve functions. Can Geotech 2001;38:53-66.

[8] Dawson A. Water in road structures movement drainage and effects. Springer: 2008. p. 436.

[9] Delage P, Howat MD, Cui YJ. The relationship between suction and the swelling properties in a he avily compacted swelling clay. Eng Geol 1998;50:31-48.

[10] Drumm EC, Reeves JS, Madgett MR, Trolinger WD. Subgrade resilient modulus correction for saturation effects. J Geotech Geoenviron Eng: ASCE 1997;123:663-70.

[11] Escario V, Saez J. Measurement of the properties of swelling and collapsing soils under controlled suction. In: Proc 3rd int conf expansive soils, Haifa, Israel; 1973. p. 195-200.

[12] Esteban F. Caracterización de la expansividad de una roca evaporítica. Identificación delos mecanismos de hinchamient. Ph.D. thesis. Santander: Universidad de Cantabria; 1990.

[13] Fawcett RG, Collis-George N. A filter paper method for determining the moisture characteristics of soil. Aust J exp Agric Anim Husb 1967:7162-7.

[14] Fleureau JM, Kheirbek-Saoud S, Soemitro R, Taibi S. Behavior of clayey soils on drying-wetting paths. Revue Canadienne de Géotechnique 1993;30:287-96.

[15] François S, Karg C, Haegeman W, Degrande G. A numerical model for foundation settlements due to deformation accumulation in granular soils under repeated small amplitude dynamic loading. Int J Numer Anal Methods Geomech 2010;34(3):273-96.

[16] French Design Manual for Pavement Structures, LCPC, SETRA; December 1997.

[17] Fredlund DG, Xing A. Equations for the soil-water characteristic curve. Can Geotech J 1994;31:521-32.

[18] Gardner R. A method for measuring the capillary tension of soil moisture over a wide moisture range. Soil Sci 1937;43:227-83.

[19] Gomes Correia A. Unbound granular materials - laboratory testing, in-situ testing and modelling. Rotterdam: A.A. Balkema; 1999.

[20] Habibalah T, Chazallon C. An elastoplastic model based on the shakedown concept for flexible pavements unbound granular materials. Int J Numer Anal Methods Geomech 2005;29:577-96.

[21] Hornych P, Kazai A, Piau JM. Study of the resilient behaviour of unbound granular materials. In: Proceedings 5th conference on bearing capacity of roads and airfields, Trondheim, vol. 3; 1998. p. 1277-87.
[22] Khoury NN, Zaman MM. Correlation between resilient modulus, moisture variation, and soil suction for subgrade soils. Transport Res Rec, No. 1874 Washington, DC; 2004. p. 99-107.

[23] Konrad JM, Ayad R. Desiccation of a sensitive clay: field experimental observations. Can Geotech J 1997;34:929-42.

[24] Li D, Selig ET. Resilient modulus for fine-grained subgrade soils. J Geotech Eng: Am Soc Civil Eng 1994;120(6)

[25] Nowamooz H, Masrouri F. Hydromechanical behaviour of an expansive bentonite/silt mixture in cyclic suction-controlled drying and wetting tests. Eng Geol 2008;101:154-64.

[26] Nuth Laloui. Effective stress concept in unsaturated soils: clarification and validation of a unified framework. Int J Numer Anal Meth Geomech 2008;32:771-801.

[27] Rababah SR. Integrated assessment of free draining base and subbase materials under flexible pavements. PhD thesis. USA: University of Akron; 2007.

[28] Rada G, Witczak MW. Comprehensive evaluation of laboratory resilient moduli results for granular material. Transport Res Rec 1981;810:23-33.

[29] Rahardjo H, Lee TT, Leong EC, Rezaur RB. Response of a residual soil slope to rainfall. Can Geotech J 2005;42:340-51.

[30] Richards LA. Capillary conduction of liquids through porous medium. Physics 1935;1:318-33.

[31] Richards LA, Gardner W. Tensiometers for measuring the capillary tension of soil water. J Am Soc Agron 1938;28:352-8.

[32] Seyhan U, Tutumluer E, Yesilyurt H. Anisotropic aggregate base inputs for mechanistic pavement analysis considering effects of moving wheel loads. J Mater Civil Eng: Am Soc Civil Eng 2005;17(5):1-8.

[33] Suiker ASJ, de Borst R. A numerical model for cyclic deterioration of railways tracks. Int J Numer Methods Eng 2003;57:441-70.

[34] Tarantino A, Mongiovi L. Experimental procedures and cavitation mechanisms in tensiometer measurements. Geotech Geol Eng 2001;19:189-210.

[35] van Genuchten MTH. A closed-form equation for predicting the hydraulic conductivity of unsaturated soils. Soil Sci Soc Am J 1980;44:892-8.

[36] Villar MV. Investigation of the behaviour of bentonite by means of suction controlled oedometer tests. Eng Geol 1999;54:67-73.

[37] Yuan D, Nazarian S. Variation in moduli of base and subgrade with moisture. In: Transportation Research Board 82nd annual meeting, Washington, DC, 1216 January 2003 [CD-Rom].

[38] Zur B. Osmotic control of the matric soil water potential: I. Soil water system. Soil Sci 1966;102:394-8. 